\title{
La imagen negada Mito e ideología en la imagen de la persona con $\mathrm{VIH}$
}

\author{
José CUEVAs MARTíN \\ Universidad Complutense de Madrid \\ joscueva@pdi.ucm.es \\ Pilar APARICIO AZACÁRRAGA \\ Instituto de Salud Carlos III \\ paparicio@isciii.es \\ Begoña MANSO FERNÁNDEZ \\ Heliópolis Producciones \\ begusda@hotmail.com
}

Recibido: 12-05-2012

Aceptado: 10-10-2012

\begin{abstract}
Resumen
Este artículo se centra en aquellos aspectos mitológicos e ideológicos que afectan a la imagen de la persona que vive con el virus de inmunodeficiencia humana (VIH) y su incidencia en la producción de audiovisuales destinados a formar parte de programas de prevención de esta enfermedad en jóvenes. La dualidad imagen- no-imagen constituye un binomio fundamental para el estudio del papel que desempeña la imagen técnica como elemento de identidad y formación de mito en la persona que vive con VIH y, consecuentemente, para articular obras de prevención sustentadas en narrativas audiovisuales del género documental.

Se parte de un estudio cualitativo basado en un conjunto de testimonios recogidos en forma de entrevista a personas con VIH en El Salvador y España. El material registrado en formatos vídeo y audio comprende un total de 27 entrevistas de larga duración (entre 60 y 90 minutos por término medio), que sirvieron de fuente de información y documentación para la realización del documental Yo soy positivo ¿y tú?, película destinada a la prevención del VIH en la población joven de ambos países. La reflexión parte de la decisión tomada por cada uno de los entrevistados de hacer o no visible su condición de seropositivo, así como del tratamiento audiovisual que se consideró más apropiado y posible con fines preventivos. Se analiza la relación signo- no signo de una realidad que puja por hacerse visible y que se debate entre la ciencia y el mito.
\end{abstract}

Palabras clave VIH, SIDA, imagen, mito, ideología, prevención, documental 


\title{
The negated image \\ Myth and ideology in the image of HIV persons
}

\begin{abstract}
This article examines some mythological and ideological elements related to the social and personal image of people who live with HIV (Human Immunodeficiency Virus), with reference to implications for film production as part of prevention programs for young people. The duality image/non-image represents an essential factor in the analysis of the relationship established between technological images, self-identity and myth conformation regarding HIV people, and consequently in the production of documentary films for the prevention of HIV.

Our approach, mainly qualitative, is based on a series of testimonies of HIV people interviewed in El Salvador and Spain. The recorded material covers 27 interviews in audio and video formats of approximately 60 to 90 minutes each. This material was recorded initially for the film Yo soy positivo ¿y tú?, a documentary planned to be part of a prevention program on HIV for the young population of the above mentioned countries. Our analysis is marked by a dual fact: the decision of the interviewed subjects to make visible or not their condition as a person living with HIV and the limitations this might have for appropriate audiovisual treatment of this issue. Consequently, our investigation focuses on this sign/ non- sign dilemma of a reality which struggles to become visible and is torn between science and myth..
\end{abstract}

Key words: HIV, AIDS, image, myth, ideology, prevention, documentary.

\section{Referencia normalizada}

Cuevas Martín, M., Aparicio Azacárraga, P., Manso Fernández, B. (2013). "La imagen negada. Mito e ideología en la imagen de la persona con VIH”. Política y Sociedad, Vol.50 Núm. 2 707-732

Sumario: Introducción. 1.Antecedentes. 2.Objeto de estudio. 3.Metodología. 4.La representación social de la enfermedad. 5.Enfermedad, imagen técnica e imagen mental. 6.Metáfora y enfermedad. 7.Enfermedad y mito. 8.Imagen e ideología. 9.Tratamiento audiovisual. 10.Conclusiones. Bibliografía

\section{Introducción}

En 2009, un grupo de médicos e investigadores del Instituto de Salud Carlos III de Madrid (ISCIII) vio la conveniencia de emprender un proyecto de prevención del VIH en adolescentes y jóvenes para España y América Latina dado el incremento significativo de la tasa de incidencia en esta población durante los últimos diez años. La oportuna realización de estudios epidemiológicos, de la prevalencia, conductas de riesgo y de opinión llevados a cabo previamente en la población joven de España y El Salvador, aconsejaron la creación de un programa piloto preventivo en el que destacasen distintas intervenciones de sensibilización tales como talleres didácticos, materiales divulgativos, acciones de información comunitarias y la producción de un audiovisual. El conjunto de estas medidas se diseñó con la intención de que pudiera trasladarse posteriormente al conjunto de los países hispano hablantes. 
Partiendo de estas premisas, se fijó como primera meta la formación de un programa de prevención del VIH destinado a los jóvenes que pusiera especial énfasis en el riesgo de adquirir el virus por transmisión sexual. Para llevar a la práctica el proyecto, el ISCIII solicitó la colaboración de la Liga Española para la Educación, organización no lucrativa dedicada a la realización de programas educativos con jóvenes del ámbito de América Latina y España, y el patrocinio del proyecto a la AECID (Agencia Española de Cooperación Internacional y Desarrollo). Una vez conseguida esta estructura operativa, se inició el conjunto de tareas del programa, incluida la producción del documental.

Entre los meses de junio de 2008 a enero de 2009, el equipo de producción audiovisual se dedicó a tareas de investigación y documentación, estableciendo múltiples contactos con médicos, ONGs, psicólogos y trabajadores sociales, especialistas en VIH/SIDA, profesores de enseñanza secundaria, maestros de escuelas primarias, amigos y familiares, y personas conviviendo con el virus de ambos países. Durante este periodo se llevaron a cabo numerosas entrevistas a representantes de todos estos colectivos, entre las que cabe destacar las realizadas a grupo de personas con el virus, en edades comprendidas entre 17 y 45 años. A finales de enero de 2009 se comenzó el proceso de rodaje del documental con la grabación de entrevistas en vídeo a todos aquellas personas con VIH que dieron su consentimiento (ver tablas para mayor detalle). En mayo de ese mismo año se finalizó el montaje del documental con el nombre Yo soy positivo ¿y tú? (Cuevas, 2009) y acto seguido se presentó públicamente en un doble acto en España y El Salvador.

\section{Antecedentes}

Entre los numerosos estudios realizados sobre la representación social de esta enfermedad y del uso del audiovisual y de la fotografía en los programas de prevención del VIH, destacan los artículos dedicados a analizar el impacto o afectividad negativa que el VIH/SIDA proyecta sobre la población en general (Páez, 2011), y aquellos otros que valoran la capacidad de comunicación que tienen determinados géneros y formatos audiovisuales, ya sean de ficción (Igartua, 2002) o spots publicitarios (Bretón-López, 2005) en distintos grupos sociales diferenciados por sexo, edades, renta, etc. Asimismo, encontramos numerosos trabajos dedicados a analizar el tratamiento que recibe el VIH/SIDA en los medios de comunicación, especialmente en la prensa escrita de ámbito nacional e internacional (Revuelta, 2002; Terrón, 2011; Santos, 2005) y estudios que analizan la enfermedad desde la perspectiva de la iconografía, el arte (Martín, 2006) y la fotografía documental (Schonberg, 2002).

Una vez revisada esta bibliografía, entendemos que nuestra discusión complementa las aportaciones de estos autores si tenemos en cuenta que nuestra experiencia se centra, dentro de la producción audiovisual, en el género documental como método de comunicación y de tratamiento iconográfico de la enfermedad, que las fuentes de información, en este caso, son directas, a través de los testimonios de 
vida de un grupo de personas que viven con el virus, y que nuestra perspectiva es eminentemente cualitativa, fruto de la relación interpersonal establecida entre el objeto de filmación, en este caso las personas con VIH y el equipo de documentalistas.

De acuerdo con nuestra investigación, hasta la fecha de inicio de la preproducción del documental, no se había realizado en lengua castellana ningún documental o audiovisual de prevención del VIH en el que se mostraran testimonios directos de personas con VIH en su mayoría jóvenes que hubieran adquirido el virus por transmisión sexual, y preferentemente por relaciones heterosexuales ${ }^{1}$.

\section{Objeto de estudio}

El conocimiento científico del VIH/SIDA desde los primeros casos aparecidos en 1981 hasta nuestros días ha sufrido grandes transformaciones. Esta continua adaptación del saber a los acontecimientos nos sugiere que la enfermedad es un hecho altamente dinámico y variable en el tiempo, y que nuestra apreciación de la misma es siempre histórica. Somos conscientes de que en la catalogación de las enfermedades prima a veces la necesidad imperiosa de ordenar, tal vez con el prurito de despejar nuestras propias limitaciones e inseguridades (Gilman, 1994:8); de aquí que se haya producido una reestructuración conceptual y terminológica de esta enfermedad a lo largo de los años desde unos primeros momentos de incertidumbre ante un fenómeno desconocido hasta la progresiva delimitación de su etiología a partir de la observación, descripción y análisis de los hechos. La primera etapa de dudas comenzó a cerrarse hacia principios de los ochenta una vez que quedó acuñado el término SIDA (1982) (Gilman, 1994:247), y de forma más determinante al ser detectado dos años más tarde el virus causante de este síndrome (Collins, 2002:1). Posteriormente, en mayo de 1987, se dio un nuevo paso en esta dirección una vez que el Comité Ejecutivo del Comité Internacional de Taxonomía de Virus aconsejó el uso de las siglas VIH para delimitar la existencia y propiedades del Virus de Inmunodeficiencia adquirida Humana, causante de la enfermedad.

Este proceso histórico sufrió un nuevo avance con la aparición de los antirretrovirales de alta eficacia en 1996, conjunto de fármacos que hizo posible que el VIH/SIDA pasara de ser una enfermedad inexorablemente mortal a convertirse en un síndrome de evolución crónica. Este avance de la farmacología marca un punto de inflexión en la construcción de la representación social de la enfermedad al

${ }^{1}$ Conviene destacar en este contexto la obra singular llevada a cabo en Estados Unidos por madres enfermas de sida que se grabaron a sí mismas para dejar a sus hijos, bebés en el momento de la grabación, testimonio de su vida y experiencia con el virus. Se trata de grabaciones que no han trascendido el ámbito privado de los investigadores y de las familias. (Barnes et al, 1997:7-31). 
establecerse dos grupos diferenciados de personas con el virus atendiendo a las distintas fases de su evolución. Ni que decir tiene que el acceso o no a estos fármacos es un elemento determinante en la formación de esa representación social de la enfermedad.

Una vez delimitado este proceso histórico, hemos de puntualizar que nuestra investigación se centra en un grupo de personas que en las fechas de producción del documental se mostraban asintomáticos frente a la enfermedad. Conviene subrayar asimismo que estudiamos más de cerca la imagen de la persona con VIH como elemento clave de la representación social que se tiene del mismo en nuestros días. En nuestro estudio ha sido prioritario determinar el valor y sentido que cobra esta imagen dentro de la sociedad, como elemento de identificación, comunicación, ético, legal y político.

\section{Metodología}

Nuestra investigación parte del trabajo realizado en el documental Yo soy positivo ¿y tú?, y en cierta manera es continuación, si no una conclusión del mismo. En primer lugar, contamos con la información procedente de las veintisiete entrevistas de larga duración, y grabadas en audio, a las personas con VIH en El Salvador y España. Este estudio de campo se completó con una fase experimental en la que se verificó la disponibilidad o no de los entrevistados a hacer visible su condición de persona con VIH ante la cámara. Sus decisiones y opiniones al respecto suponen una fuente de información de suma importancia en aras de profundizar en el conocimiento del proceso de estigmatización que sufren y de aportar algunas claves para el estudio semiológico, cada vez más necesario, de la representación social de esta enfermedad (Gilman 1994:246). El análisis de la información y de los hechos se ha realizado desde una perspectiva cualitativa, dando preferencia al juicio conceptual y categórico en torno al objeto de estudio por encima de consideraciones estadísticas. Se ha intentado profundizar por este medio en temas tan cruciales como la visibilidad y el binomio imagen/ no imagen desde una perspectiva semiológica e ideológica. Somos conscientes de que en esta ocasión ha sido necesaria una mirada crítica de autorreflexión y de auto-observación del propio investigador ante una realidad que lejos de excluirle lo envuelve, y que le exige una aproximación comprometida con el objeto de estudio más allá de la disección distante propia del positivismo. Si bien es necesario un distanciamiento objetivo frente a un fenómeno como el VIH/SIDA que presenta un gran componente ideológico y mitológico en su formación, no son menos necesarios la introspección y el análisis críticos de nuestro papel como observadores frente a una realidad de la que somos parte viva. Por último, compartimos con estudios similares (Nanda y Pramanik, 2009) una serie de limitaciones metodológicas como son el haber circunscrito el estudio a un área geográfica y una población delimitadas, habernos basado fundamentalmente en el material de las entrevistas y haber adoptado una aproximación al asunto eminentemente cualitativa. 
Nuestra aproximación al objeto de estudio cabe considerarla a mitad de camino entre la antropología audiovisual y las ciencias de la comunicación, en un caso por la presencia y participación activa del investigador en la realidad que se pretende estudiar, y en el otro por el deber de adoptar una posición formal, científica e ideológica en la investigación y en la presentación de resultados. No debemos olvidar que estos últimos reciben necesariamente en el audiovisual un sentido estético, conceptual e iconográfico a posteriori de los materiales grabados, mayormente testimonios y documentos gráficos de los contextos sociales, familiares y personales en los que las personas con VIH se desenvuelven habitualmente.

Es importante señalar que, tras el periodo previo de investigación y de entrevistas, se tomó la decisión de que el mensaje de prevención fuera dado por los jóvenes a los jóvenes, y a ser posible por seropositivos pertenecientes a esa edad, que además hubieran adquirido el virus por transmisión sexual y con amplia representación de homosexuales y heterosexuales. Este requisito cumplía tanto con las exigencias de los especialistas que confirmaban una tasa de incidencia en aumento en los últimos diez años asociada a este tipo población y de conductas, como de los propios afectados, que en su mayoría apostaron porque fueran ellos mismos los que contaran sus experiencias frente a la cámara. Las dificultades para vencer este obstáculo planearon sobre todo el proceso de producción del documental y configuran el eje central sobre el que se articula esta contribución.

La población de entrevistados y sus características más sobresalientes en cuanto a género, países y medios técnicos de grabación (audio y audiovisual), quedan reflejadas en los siguientes cuadros.

Cuadro 1: Población entrevistada por género y país

\begin{tabular}{|l|c|c|c|}
\hline & HOMBRES & MUJERES & TOTAL \\
\hline ESPAÑA & 9 & 7 & 16 \\
\hline EL SALVADOR & 8 & 3 & 11 \\
\hline TOTAL & 17 & 10 & 27 \\
\hline
\end{tabular}

Cuadro 2: Entrevistas por país, en audio y vídeo

\begin{tabular}{|l|c|c|c|}
\hline & AUDIO & AV & TOTAL \\
\hline ESPAÑA & 13 & 3 & 16 \\
\hline EL SALVADOR & 2 & 9 & 11 \\
\hline TOTAL & 15 & 12 & 27 \\
\hline
\end{tabular}

Todos los participantes adquirieron el virus por prácticas sexuales de riesgo a excepción de Yolanda (20 años), que lo contrajo por transmisión vertical, y Eva, 
que nos ofreció su testimonio y experiencia como madre de una hija de 8 años, portadora del virus, adquirido por transmisión vertical.

Es importante reseñar en este apartado un factor que afectó decisivamente nuestra aproximación al objeto de estudio: en la práctica totalidad de las entrevistas se puso en evidencia desde un primer momento el recelo de los sujetos a participar en el proyecto con su imagen por razones de discriminación, fenómeno que viene siendo habitual en la investigación del VIH/SIDA (Terrón, 2011:16). La mayoría expresó su preocupación por la finalidad y el uso posible que podría darse a sus intervenciones ${ }^{2}$, y aquellos que permitieron ser grabados en vídeo exigieron el control sobre los materiales editados.

\section{La representación social de la enfermedad}

Cada periodo histórico tiende a presentar una enfermedad que simboliza y opera como metáfora de los problemas de la sociedad del momento (Páez, 1991b:103). Así, se ha venido relacionando la lepra con la Antigüedad, la peste con la Baja Edad Media (Siglo XIV), la sífilis con la sociedad occidental del siglo XV, la tuberculosis con la de finales del XIX, el cáncer con el siglo XX, y el Sida con la sociedad posmoderna y globalizada que se inicia a finales del siglo XX y que se extiende hasta nuestros días (Páez, 1991b:111). No sería aventurado afirmar por tanto que el VIH/SIDA es la enfermedad que mejor ejemplifica las contradicciones del capitalismo avanzado, caracterizado por un proceso de globalización continuo, migraciones a nivel planetario, redes internacionales de informática y telecomunicaciones, y desastres medioambientales. Posiblemente el VIH/SIDA es un fruto más del proceso de enajenación que sufren las sociedades modernas, sustentadas en un desarrollo tecnológico espectacular y sin precedentes en la historia de la humanidad, y unas relaciones de producción y poder desiguales y desequilibradas. Los procesos de globalización descontrolados están avivando la propagación a nivel internacional de epidemias hasta ahora desconocidas, entre las que debemos incluir el VIH/SIDA con una cifra que supera hasta la fecha los cinco millones de muertos en el mundo.

En este sentido, el VIH/SIDA da continuidad a un modelo de representación ya instaurado en su día por la tuberculosis, en el que la imagen del "enfermo" se asocia a una enfermedad crónica, si no necesariamente mortal, sí fuertemente estigmatizada de acuerdo con la clase social, país, edad o género del paciente (Páez, 1991b:31). La entrada en acción de los antirretrovirales y el acceso a ellos ha permitido que la enfermedad haya ido perdiendo su capacidad de transformar el cuerpo y hacer visibles sus síntomas. De todos modos, conviene recordar que estas representaciones de lo enfermo coinciden en entender el binomio enfermedad- salud desde la

${ }^{2}$ Una de estas entrevistas tuvo que ser anotada a mano, sin poder ser grabada tan siquiera en audio, por requerimiento expreso del entrevistado. 
individualidad, como un proceso que está ligado a un sujeto en particular y no a una colectividad. Son modelos de ver por tanto extremadamente individualistas en consonancia con una visión marcadamente biológica y productiva. En el caso del VIH/SIDA esta percepción sesgada se extiende, como veremos, a grupos, colectivos, gremios, pero sin llegar nunca a comprenderlo como un proceso social, colectivo e interdependiente.

En la imagen social del VIH/SIDA se suelen distinguir tres etapas bien diferenciadas en el periodo que comprende desde la detección de los primeros casos hasta nuestros días. En un primer momento la enfermedad se asoció con grupos de riesgos muy definidos y aglutinados por las siglas HHHH: haitianos, hemofílicos, homosexuales y heroinómanos. A medida que la investigación científica en el campo biomédico, de la biología molecular y de las ciencias sociales fue avanzando, esta visión parcial y discriminatoria fue abriendo espacio a una nueva dispuesta a asociar la enfermedad mayormente con conductas de riesgo. En la actualidad nos encontramos inmersos en una tercera etapa que vuelve a establecer una relación directa de la enfermedad con colectivos que son representados mayormente por extranjeros, africanos, tercer mundo, pobreza o mujeres (Bueno y Yaosca, 2002:169). Otros autores han ofrecido clasificaciones de este proceso histórico atendiendo más de cerca al tratamiento que los medios de comunicación de masas han dado de la enfermedad (Revuelta et al, 2002). Así, contaríamos con una era inicial de sorpresa y desconcierto en la sociedad, seguida de una etapa de atención científica, de otra más humanizada y solidaria, ligada a figuras mediáticas que hicieron pública su condición de enfermos (Rock Hudson y Magic Johnson), para concluir en una última etapa definida como política, o de compromiso en la que cabe destacar la lucha de los propios colectivos de enfermos en la reclamación y normalización del uso de terminologías que afectan a la realidad de la percepción social. Nuestro parecer apuesta por entender este proceso histórico como un continuo caracterizado por la pervivencia y confrontación de dos actitudes básicas ante la enfermedad, representadas por la superstición y la ciencia. Esta doble representación social, que ha sido adjudicada en ocasiones al binomio racional/ "natural", científica/ "naif" (Jodelet, 1991:24-31), no es exclusiva del VIH/SIDA, la encontramos en gran número de enfermedades, normalmente ligadas a contextos sociales en los que la desinformación y/o la ausencia de infraestructuras y de atención médicas juegan un papel de primer orden. De este modo, la representación científica en el caso del VIH/SIDA se ve obligada a convivir, cuando no a someterse a una imagen social de la enfermedad cargada de metáforas, mitos e ideología que avivan la exclusión y el repudio cuando no la negación misma de la identidad de la persona que vive con el virus. La representación social de la enfermedad, por consiguiente, no se construye solamente a partir de una iconografía determinada, o del conocimiento que se tiene de ella, sino que en su gestación participan otros elementos provenientes de la cultura, la religión, la medicina, los géneros, la sexualidad, etc. Esto hace que quede marcada por una moral e ideología que se presentan como natural, bajo la forma de un pretendido sentido común, a modo de un conocimiento "vulgar" que hace pervivir todo un entramado simbólico repleto de elementos no 
verbales, imágenes, figuras y afectos inconscientes e irracionales (Páez, 1991c:57) sobre el que se justifica la exclusión.

\section{Enfermedad, imagen técnica e imagen mental}

El interés por lograr una representación del cuerpo o de los fenómenos patológicos que en él se producen, acorde con la visión proporcionada por la perspectiva, y con las necesidades de los naturalistas y médicos de la época, se remonta al Renacimiento. Hacia finales del siglo XV comienzan a proliferar los grabados y dibujos que muestran, unas veces, el funcionamiento y la posición de los órganos con una finalidad didáctica y, otras, como es el caso de Leonardo o Vesalio, láminas de estudios anatómicos con un alto grado de descripción, fieles o próximas a las leyes de la perspectiva. Cabe destacar entre este tipo de láminas un grabado de Durero, de 1496, que representa un enfermo aquejado de sífilis o "mal de Nápoles".

Esta nueva forma de ver el cuerpo bajo la visión de la ciencia y de sus instrumentos ópticos se extrapoló a la enfermedad, imponiéndose un modelo racional de ver lo orgánico bajo la construcción de un espacio reglado por el nuevo canon establecido por la perspectiva. Este modo de representación tuvo su continuidad en los siglos posteriores una vez que los dispositivos ópticos fueron perfeccionándose de la mano del avance científico y técnico, hasta culminar con la llegada de la fotografía y los dispositivos electrónicos de producción de imágenes tecnológicas.

En sus primeros años de existencia, la fotografía atrajo el interés del colectivo médico con la aplicación del daguerrotipo y del talbotipo a la fotomicrografía de los fluidos corporales, células, cabellos, en pos de descubrir nuevas fuentes de conocimiento. A mediados del siglo XIX aparecieron los primeros registros fotográficos relacionados con intervenciones médicas, la discapacidad y la enfermedad. Cabe destacar en este contexto la búsqueda de pistas fisiológicas de los retratados en el transcurso de estados provocados por el sueño o la hipnosis (Eder, 1888:192), por distintas psicopatologías, como es el caso de los estudios de Charcot; los primeros ensayos de prospección del fondo de ojo por medios fotográficos(Eder, 1888:184), las primeras endoscopias de laringe o del tracto digestivo registradas fotográficamente(Eder, 1888:188); los estudios del movimiento corporal en obesos, inválidos y parapléjicos, realizados por Muybridge; o los retratos fisiognómicos llevados a cabo por la justicia en su afán por descubrir los rasgos identificativos y comunes de delincuentes y criminales, práctica similar a aquella ejercida por los antropólogos en los estudios antropométricos de tribus, familias y comunidades (Kemp, 1997:132). Desde finales de este mismo siglo, la conjunción de las sales de plata con la electrónica y otras fuentes de radiación más allá de la luz visible potenció la aparición de una gran variedad de instrumentación de producción de imágenes ampliamente utilizada por la práctica médica.

Esta experiencia acumulada por la ciencia médica en la utilización de la fotografía nos insta a distinguir entre dos tipos de imágenes científicas. En primera instancia, se presenta la imagen como vía directa hacia un nuevo conocimiento. En este 
caso, la imagen nos desvela nuevos aspectos de la naturaleza hasta entonces ocultos a la observación científica, para convertirse ella misma, con sus sombras y luces, sus marcas y densidades, en un nuevo objeto para el análisis y el avance científico. $\mathrm{Y}$ en segundo lugar encontramos una imagen médica al servicio de la documentación y la comunicación. Las fotografías se presentan en este caso como piezas indispensables para registrar, archivar, catalogar, identificar y comunicar hechos científicos relativos a la enfermedad, especialmente sus rasgos físicos más definitorios. En ambos casos, es la observación, pieza fundamental del método experimental, el elemento que queda potenciado y beneficiado por la llegada de la imagen tecnológica. En definitiva, la medicina hace uso de esta doble función de la imagen bien para cubrir sus necesidades de diagnóstico, análisis, detección de anomalías, descubrimiento de nuevos elementos estructurales y funcionales; bien para documentar, catalogar y comunicar resultados.

Sin embargo, la enfermedad es fuente asimismo de un nuevo tipo de imagen no contemplada hasta el momento, y que adquiere unas connotaciones muy siginificativas en el tema que nos ocupa: la persona con VIH. Pues, a esas dos vertientes de la imagen médica debemos añadir otra que es la imagen del enfermo como sujeto, persona, individuo perteneciente a un grupo, una sociedad, un país y un mundo. Es la imagen de la persona con VIH como ciudadano, su retrato fotográfico o videográfico que trasciende y obtiene una nueva dimensión más allá de la disección científica para entrar en el ámbito de la estética, la moral, la justicia, la política y la ideología. Huelga decir que en ambos casos el sujeto es el mismo, son el conocimiento y la práctica social los que se encuentran parcelados.

Sabemos que el propósito de las fotografías médicas incluidas en los manuales, revistas, o atlas especializados es mostrar los síntomas visibles de la enfermedad en el cuerpo de un enfermo, anónimo, no en el de una persona concreta con un status legal determinado. La imagen del enfermo para la medicina es la de un sujeto muestra, especimen, o caso. Esta representación positivista de lo humano que la medicina comparte con otras ramas de la ciencia obedece a un reduccionismo epistemológico práctico, utilitario, voluntario ante su objeto de estudio. Pues lo significativo en la imagen médica es la diferencia, el análisis de las partes, el contraste, lo que se aparta de lo común, la pertenencia o no de un síntoma visible a un conjunto, estructura o función propias de un cuadro patológico; ir más allá le obligaría a asumir una imagen con un significado ajeno a su método y práctica: la imagen con una dimensión social, estética, medioambiental, moral, ciudadana del enfermo. El VIH expone fehacientemente esta contradicción, pues tener el virus no conlleva necesariamente la presencia de rasgos corporales visibles que identifiquen esa condición o que puedan construir una imagen identificativa. De aquí, que la imagen médica de la persona con VIH sólo pueda echar mano de lo distintivo, en este caso posiblemente de los rasgos de lipodistrofia o de los primeros síntomas corporales debidos a una bajada de defensas, o al avance inexorable hacia la etapa sida de la enfermedad tal como quedaría manifiesto en el sarcoma de Kaposi u otras afecciones corporales visibles. La imagen pública de la persona que vive con VIH, entonces, como ser social, su imagen negada más bien en este caso, trasciende los 
propósitos de la medicina para adentrarse en el ámbito de interés de las ciencias de la información, de la comunicación, de la antropología, o de la sociología.

En este punto de la discusión se pone de manifiesto el puente de conexión existente entre este tipo de imágenes técnicas, producto de una instrumentación avanzada y de precisión como es la foto-cine-vídeográfica, y aquella otra imaginaria, fruto de la representación social. El hecho de que ésta última se alimente de signos o, si se prefiere, de imágenes provenientes de otras realidades, enfermedades o estados de enfermedad, atribuye un claro protagonismo a la imagen mental, como representación personal, individual de los hechos. Esta se construye internamente en base a la estimulación circundante (imágenes técnicas incluidas) y la imaginación y la fantasía del receptor. Por último, esta actividad iconográfica del yo cobra una dimensión social a modo de imaginario por alimentarse de elementos comunes y ser compartida por diferentes capas y grupos sociales, por la cultura y la ideología.

En resumen, debemos centrar nuestra atención en esta triple construcción de imágenes en torno a la enfermedad: la imagen técnica, que se forma a partir de la luz y otras radiaciones con la ayuda de distintos instrumentos de captación y reproducción más o menos automatizados, y cuyos fines son públicos y/o científicos; la imagen mental que se construye en el interior de nuestras mentes como representación de lo externo, a modo de "vorstellung" personal e íntimo, y avivada por recuerdos, fantasías y contenidos inconscientes; y la imagen o representación social, construida colectivamente en terreno de nadie bajo un acuerdo tácito e intangible, sin normas o directrices aparentes, y existente en el substrato cultural, colectivo, a modo de imagen mental socializada, o imaginario. Las tres imágenes se influencian y retroalimentan con un trasiego continuo de elementos estéticos, perceptivos, simbólicos, epistemológicos y constructivos (Jodelet, 1991:38) como base material, informacional e ideológica del ubicuo y onmnipresente universo iconográfico de las sociedades modernas.

\section{Metáfora y enfermedad}

La traslación de significantes y significados de un signo a otro para dar un sentido figurado a lo que se expresa caracteriza la metáfora. En el lenguaje natural es la palabra que se aplica a un objeto o a un concepto con el fin de sugerir una comparación y facilitar su comprensión (RAE). La metáfora da el nombre de una cosa a otra, traspasa el significante y significado de una palabra a un nuevo contexto o frase donde adquiere un poder evocador, un nuevo significado fruto de su unión con otras palabras. Se establece así un doble sentido, uno literal y otro figurado. En otras palabras, sería "llevar más allá", por analogía entre dos términos, la capacidad de comunicación del lenguaje. Se produce un cambio semántico a partir de la conjunción de dos imágenes diferentes pero que guardan una afinidad conceptual. En términos iconográficos, podríamos decir que se adjudica una imagen ajena, pero relacionada con el hecho que se quiere expresar, a otros términos para facilitar su compresión o provocar, potenciar o magnificar nuevos significados. En definitiva, 
es cargar un significante con imágenes y semas provenientes de otro significante cuyo significado se evoca en el primero por proximidad semántica (concepto), emocional o analogía audio y/o visual. Si en la literatura la metáfora despliega gran versatilidad y riqueza, materializadas en las infinitas posibilidades que nos ofrecen por ejemplo los lenguajes vulgar y poético, en lo social las metáforas se construyen sutilmente pero con un sentido inequívoco, funcional y pragmático al servicio de la ideología. En el ámbito de la enfermedad, Susan Sontag ha señalado certeramente esta función omnipresente y decisiva en patologías altamente estigmatizadas como el cáncer y el sida (Sontag, 1996). Esta última, por ejemplo, ha sido asociada insistentemente a figuras y conceptos tales como arma letal, látigo, espía, agente oculto, castigo divino, plaga... combate, una amenaza para la seguridad nacional (Espinel, 2003:132), hecho que ha promovido la construcción de una representación social parcial y repleta de prejuicios. Diríamos que la metaforización de un hecho, en este caso de una enfermedad, supone un primer nivel de comunicación portador de una carga semántica latente. Se pretende con su uso ir más allá de lo expresado mediante la asociación de un término a un hecho con sentido reafirmante, alegórico, incisivo, ligeramente contaminante de otros semas tomados de otras realidades. Y decimos ligeramente porque pretende pasar inadvertido, oculto tras un primer envoltorio semántico, añadido inocente e inocuamente, como puro subterfugio de una ideología que se presenta dada, ingenua y natural. En el caso de las enfermedades malditas, la jerga punitiva, militar, de combate, de acoso, de peste moderna queda adjudicada a la descripción y definición de los hechos con el prurito de reforzar la comunicación, no tanto con la intención de añadir o completar significado cuanto con el deseo de evocar un estado de alerta y peligro con el uso de una imagen anexa, cargada de emotividad cuando no de violencia. En el caso del VIH/SIDA, la metáfora militar nos sitúa frente a un lugar para la batalla; en la metáfora médica se afianza el sentido de encontrarnos ante un mal a extirpar, en la biológica frente a un enemigo encubierto que nos acosa e invade como si de un virus informático se tratara (Sontag, 1996:41), y en la metáfora religosa, pongamos por caso el catolicismo, sale a relucir como un castigo divino, "un flagelo", "una nueva y amenazadora calamidad" (Wojtyla, 1989). Por contraposición, la enfermedad se convierte a menudo en metáfora de lo que se considera descomposición social, política, económica o de la personalidad; así es frecuente toparnos con expresiones del tipo: "un cáncer de las sociedades modernas", "virus informático", "un tumor a extirpar", o "... se ha venido manifestando una especie de inmunodeficiencia en el plano de los valores existenciales, que no puede dejar de reconocerse como una verdadera patología del espíritu" (Wojtyla, 1989).

Y si la metáfora supone un primer nivel de transformación del sentido de la comunicación que redunda en una ideologización del mensaje, el segundo nivel de carga semántica, en esta ocasión más latente y arduo de descifrar, se corresponde con la construcción del mito.

\section{Enfermedad y mito}


El mito, como decimos, por principio se resiste a ser descifrado, deconstruido o interpretado, pues tan pronto como es comprendido pierde su fuerza de persuasión, de encandilamiento. Hay mitos que se desvanecen en pocos años, otros resisten el paso de los siglos. La enfermedad estigmatizada está cargada de mito. Más aún si se trata de una enfermedad ligada a la sexualidad, el placer, la embriaguez y lo prohibido como es el caso del VIH/SIDA. El mito en este caso se convierte en la excusa perfecta para justificar su estigmatización y respaldar la falta de libertad y derechos de aquellos que vulneran la norma tabú. Si en la metáfora se incorpora un nuevo significado para evocar y realzar la comunicación, en el mito es un signo que se metamorfosea en otro y adquiere solapadamente un efecto embaucador, seductor, incluso letárgico. Se trata más de un efecto que de un nuevo significado dado que no se mueve en la esfera de la razón o de los conceptos sino del sentimiento, del sentido del placer y del dolor. En la sociedad clásica, ya Platón señaló esta correspondencia del mito con lo emocional. El mito, para este filósofo, pertenece al cuento, a la narración, a las historias; no remite pues a la razón, sino a lo emotivo. Le ocurre algo similar al gusto estético, de ahí su proximidad. La belleza es tan intangible como el mito. Sin embargo, mientras la primera entronca con el espíritu de la época y devuelve al mundo una imagen liberadora, el segundo "transforma la historia en naturaleza"(Barthes, 2009:186).

Se quiere presentar como un hecho esencial, como parte de una norma o creencia cuando en realidad es esencialmente histórico. De ahí que sea reivindicado por la semiología como objeto de estudio al tratarse de un habla, de un habla "despolitizada" (Barthes, 2009:186). El mito constituye, según Levi-Strauss, una nueva unidad semiológica: los "mitemas" (mito+sema), unidades superiores del lenguaje por encima de los fonemas, morfemas o semantemas. (Lévi-Strauss, 1968:233). ¿O deberíamos adjudicarlo a la criptología? Porque es evidente que el mito se resiste a ser interpretado, su mecanismo opera desde los estratos inconscientes personales y colectivos, como si de una neurosis o de un sueño se tratara, para desde allí ejercer su fuerza y dominio.

En el caso de la imagen mitificada, encontraríamos un valor polivalente. Pongamos, por ejemplo, el retrato. Dispondríamos aquí de un doble camino tan pronto como tomemos de modelo la Naturaleza o la Idea. En el retrato del natural el sujeto está provisto de historia, de verosimilitud; la relación entre el significante y el significado es directa, lineal, inequívoca; la forma se supedita al objeto. Lo natural esquiva lo épico, grandilocuente, amanerado; en suma, lo impostado, lo ahistórico y descontextualizado. Por el contrario, el retrato como mito se construye tal como señala Barthes siguiendo un proceso doble. El signo, unión de un significante y un significado, pasa a ser significante de un nuevo signo al que se le asocia un nuevo significado donde se emplaza un concepto. Esta nueva unión da lugar al mito, como nuevo signo repleto de significación y de ideología.

Que el mito sea un habla, un signo, coincide con lo expresado por Lévi-Strauss, que lo considera un modo particular de la comunicación humana, un elemento que cobra sentido en el universo semiológico del ser humano, sobre una estructura de fondo por lo general inconsciente. Sin embargo, el mito se emparenta con la ideolo- 
gía en el sentido de que viene a resolver o a paliar los efectos de una contradicción en lo social y político. "Nada se asemeja más al pensamiento mítico que la ideología política. Tal vez, ésta no ha hecho más que reemplazar a aquél en nuestras sociedades contemporáneas." (Levi-Strauss, 1968:188). Si la ideología, como señaló el marxismo, es el reflejo invertido de las relaciones de producción tal como sucede con las imágenes proyectadas en la cámara oscura, el mito asume igualmente en su representación deformada, sublimada o impostada las contradicciones de lo social y de lo humano. "... el objeto del mito es proporcionar un modelo lógico para resolver una contradicción" (Lévi-Strauss, 1968:209). De aquí que las estructuras de las relaciones que lo sustentan sean decisivas para interpretar y deconstruir los contenidos simbólicos o alegóricos que se despliegan en él. El mito es un numen anclado en lo desconocido, que se alimenta de la misma fuente que la superstición; de aquí que sean sus principales valedores sacedortes, gurús, hechiceros, propagandistas, mercadotécnicos, en suma, aquellos que imponen una norma sagrada destinada a apaciguar miedos, glorificar héroes y caudillos, santificar y resucitar muertos, ensalzar divos, por medio de una deidad pagana, un ídolo ataviado y sustentado por cientos de imágenes y rituales. "... el mito y el ritual resultan ser las respuestas a la necesidad que el hombre tiene de regularidad, especialmente en los campos conceptuales y emocionales de mayor ansiedad potencial". (Kirk, 1970:37). El mito nos ayuda a aceptar la norma como eterna, como tabla inquebrantable, como ley suprema, superior y divina, como gran moral intemporal, más allá de lo "real humano". No existe pues dialéctica, contradicción, nada que vencer, ni nada que temer, el mito se encarga de todo ello.

¿Qué ocurre entonces con la enfermedad, con la enfermedad maldita, estigmatizada? En este caso el mito se construye sobre el tabú. La norma sagrada, supraestructural, que no está en los códigos sino en la conciencia general de las sociedades, es vulnerada y violada por aquél que osa hacerlo con su enfermedad, convirtiéndose él mismo en tabú. "Lo más singular de todo esto es que aquellos que tienen la desgracia de violar una de tales prohibiciones se convierten, a su vez, en prohibidos e interdictos, como si hubieran recibido la totalidad de la carga peligrosa" (Freud 1972:1761). Los tabúes legendarios que suscitaban el temor a lo diabólico, a la brujería o a los espíritus malignos fueron fuertemente asociados a la enfermedad, más aún si ésta se consideraba contagiosa y si sus rasgos visibles producían espanto. Wundt reconocía que estas formas de tabú, vividas a veces como un temor a lo demoníaco, lograban persistir en la forma de códigos y prescripciones morales posteriores (Freud 1972:1762). A esto habría que añadir que evidentemente persisten en las nuevas leyes y códigos morales, pero con mayor vehemencia si cabe en las normas sociales no escritas, que operan como tabú imponiendo su fuerza sobre las primeras. La discriminación social, laboral, familiar y sentimental que soporta la persona con VIH es norma social impuesta desde la ideología, no desde la justicia o nuestras constituciones. Y esa norma dictamina que la persona con el virus pase a ser él mismo tabú por haber infringido uno de ellos, y que su enfermedad, el repudio que sufre, e incluso su muerte, sean el castigo ejemplar prescrito por la tribu. "El hombre que ha infringido un tabú se hace tabú a su vez, porque posee la facul- 
tad peligrosa de incitar a los demás a seguir su ejemplo" (Freud, 1972:1767). El psicoanálisis freudiano en su estudio del tabú se pregunta por el trasfondo de esos demonios y de esos temores a seres albergados en el interior de la mente humana. La neurosis obsesiva fue elegida por Freud para ahondar en la etiología de esa norma, de esa prohibición. El obsesivo reproduce en su interior un proceso de formación de angustia similar al experimentado por el conjunto de una sociedad ante la vulneración de la ley. Si el rito obsesivo consigue un equilibrio ante las amenazas internas de los demonios personales, el mito y el tabú que suscitan la enfermedad mental y la contagiosa refrenan el miedo al colapso, el sentimiento de disolución y de vulnerabilidad que se vive ante su proximidad y amenaza. El falso equilibrio que consigue una neurosis en el sujeto sería pues comparable al equilibrio igualmente enajenado que impone la ideología dominante en lo colectivo. En ambos se refrena la angustia mediante una censura, una represión. En el caso del VIH esta última se consigue con la discriminación y la negación de los derechos fundamentales y de la propia identidad. La ideología dejaría de ser un producto exclusivo de los procesos mentales tal como pretende el psicologismo, que otorga una prevalencia a los procesos internos de la conciencia, o un fruto de la representación como voluntad (Schopenhauer), o de la función simbólica (Cassirer) para pasar a ser, de acuerdo con el materialismo dialéctico, un reflejo de las relaciones de poder y de producción existentes en un momento de la historia.

Nanda y Pramanik (Nanda y Pramanik 2009:110) exponen que el estigma sobre el VIH-SIDA y su correspondiente discriminación se hacen evidentes en tres niveles: el fisiológico, relacionado con el cuerpo; el social, relativo a la interacción cultural, religiosa y política; y el económico, que hace alusión al ámbito laboral y de ingresos de la persona estigmatizada. A esta clasificación estructural cabría añadir una transversal que reparte la carga de la discriminación en consonancia con el género, edad, nivel de marginación social o pertenencia a un determinado país, pues es a todas luces manifiesto que la discriminación opera diferente en cada uno de esos segmentos de la población. Tal vez sea la discriminación social de la enfermedad el elemento que mejor revela la existencia de esa norma tabú que habita por encima de las leyes fundamentales que rigen una sociedad. Una norma que impregna la conciencia no solo de los represores sino también de los reprimidos.

"No es una enfermedad porque no la sientes, es un límite social, personal, es el puto estigma. Yo lo siento (no dar su testimonio ante la cámara), pero me da terror. Me parece muy bien que hablen otros, pero yo no voy a tirar la primera piedra, no voy a ser yo el primero. Yo mismo me pongo límites, yo mismo asumo el estigma". (Antonio, 20 años)

Valga recordar aquí la discriminación por VIH en el contexto de la infancia. En este caso el temor cobra su máxima intensidad. El contacto o proximidad del VIH con los niños, bien sea porque un adulto con el virus comparte un mismo espacio con ellos, bien porque se dé la convivencia de un niño con VIH con otros semejantes, tan común en los parques de juego y escuelas, el recelo y el rechazo colectivo se 
expresa con mayor vehemencia. La norma tabú aparece con especial virulencia porque la sensación de control se derrumba y el binomio vida/muerte se pone especialmente de manifiesto. El tabú es extremo, se sabe y se oculta a un mismo tiempo. Todos sabemos que los niños con VIH están escolarizados, pero es una información que se guarda con sumo secreto (Fortuny, 2000:107).

"Ella lo ve normal, y no oculta que toma pastillas. Y ya le he dicho yo, le digo: me parece muy bien que digas que tomas pastillas, que estás mala, pero nunca digas la palabra clave. ¿Y eso? Porque te pasará lo mismo que te pasó en el colegio, y le digo: igual que nos hemos mudado de Madrid al pueblo, nos tendremos que mudar del pueblo a 3.000 kilómetros." (Eva, madre de niña con VIH de 10 años)

¿Qué proceso encontramos latente entonces en un mito que carece de imagen? Porque la persona con VIH que se muestra asintomático ante la acción del virus adolece de ella, se le deniega. Su identidad y semblante como persona que convive con un virus es rehusada por esa norma social inscrita en ninguna parte, que opera como ideología. Carecemos de significante, disponemos a lo sumo de uno vacío al que se le adhiere un significado procedente de otro signo, de otra imagen que no es otra que la de la enfermedad en su estado avanzado. Se favorece y potencia un significado que se alimenta de una iconografía bien determinada, aquella que procede de las calamidades de las regiones y países paupérrimos del planeta, del enfermo terminal, del personaje célebre aquejado del mal, de la silueta o del desenfoque vergonzosos con que son presentados sus testimonios ante las audiencias televisivas; en definitiva se asocia a personajes, grupos, colectivos, etnias de riesgo cuando no a conductas; el signo se llena de "naturalidad" procedente de otra realidad, "se le ha quitado la memoria, no la existencia" (Barthes, 2009:180). Se trata pues de una coartada, de una disculpa expuesta e impuesta por la norma, ya que con su ocultamiento obligado lo convierte irremisiblemente en tabú, o en pecado. Se particulariza y personaliza como forma de expiación, para ahuyentar la idea de que a todos nos atañe. De ahí la necesidad de matizar y de comunicar convenientemente las experiencias de vida de las personas con VIH que deciden hacerse visibles ante las cámaras en tanto en cuanto no se asocie su imagen de forma directa a un grupo de riesgo (Bueno y Yaosca, 2002:157). Pongamos por caso a Guillermo, de 27 años, que expuso su testimonio de vida con valentía y claridad ante la cámara de Yo soy positivo ¿y tú?, y que fue motivo recientemente de un artículo periodístico en uno de los seminarios de mayor tirada en España (El País Semanal (19/11/2011). Su testimonio aislado, como persona con VIH y homosexual, en un desierto informativo que no se prolija en ofrecer historias de vida de personas con VIH ¿favorece la percepción de encontrarnos frente a una enfermedad afín a grupos o conductas de riesgo? La visibilidad de la persona con VIH, su imagen pública como seropositivo representa el nudo gordiano de este dilema.

Es el tema de la visibilidad, que es tan importante. Sin visibilidad no hay ningún reconocimiento y es más complejo que el hecho de decir o no tu homosexualidad, porque en el caso de una persona seropositiva yo creo que se encuentra con una estrategia de doble armario: si lo dices te vas a encontrar con unos problemas, pero si 
no lo dices tienes unos problemas de conciencia y también quizás otros futuros que se puedan derivar de cuando la gente lo pueda descubrir ¿¿no? (Guillermo, 27 años)

El mito se alimenta de imágenes, máxime en una cultura moderna que lleva abasteciéndose de ellas a un ritmo trepidante desde la aparición de los medios de reproducción técnica, especialmente la fotografía y la amplia panoplia de procesos fotomecánicos derivados de ella. Se quiera o no, el mito y la ideología se construyen sobre imágenes, incluso en aquellos casos, como el VIH, que se levanta sobre su negación y ausencia.

Claro, es que la imagen que tienes del sidoso, con la cara deformada, con las infecciones, ya no es actual. Es que no creo que haya una imagen ahora mismo de una persona con vih, real, en la sociedad. La gente no tiene una imagen. (Paco, 30 años)

En resumen, la norma social se apodera de las conciencias individuales y colectivas, y se perpetúa a través de cuentos y leyendas, rumores, epístolas y parábolas, y de la presencia y negación de imágenes. Frente a ella y a su poder no escrito sólo queda el análisis mitológico y la acción política.

\section{Imagen e ideología}

Si el mito es un sistema semiológico de segunda generación (Barthes. 2009:173) por construirse sobre los cimientos de un signo anterior que toma como punto de partida, que desvirtúa al anexarle una significación nueva, no pactada, a modo de subterfugio ¿qué ocurre cuando partimos de una imagen negada, cuando se construye sobre un ocultamiento? Aquí resalta la polaridad existente entre el mito que se edifica sobre la base de una imagen idealizada y aquel otro que lo hace sobre una negación. Esta dicotomía se pone de manifiesto de manera singular en la iconografía que hace mito de la mujer, en esos casos extremos que van, pongamos de ejemplo, desde la estrella, diva o modelo a aquella otra obligada a ocultar su identidad bajo la indumentaria de un hábito o de un burka (Tamzali, 2010: 182).

La negación de la imagen construye un mito cuya función primera es resolver una contradicción en lo social. En unos casos, como en la imposición del burka, responderá a los requerimientos de una norma establecida (islámica, talibán) que aboga por el recato y la sumisión de la mujer a unas leyes que pretenden regular su virginidad, su poder de seducción, su incitación al pecado; y, en otros, como es el caso de la persona con VIH, imponer un silencio sobre unas conductas que son consideradas promiscuas, pecaminosas, desenfrenadas e inmorales. En el primer caso se resuelve una contradicción inherente a un sistema social con un régimen de libertades que está en consonancia con su sistema de producción y con su dependencia de otros países (grado de colonización): la mujer pasa a desempeñar una función económica y social propia de un sistema enraizado en el patriarcado, debe ocultar su identidad bajo la protección del mito. En el segundo caso, la ausencia de imagen, su negación pública, resuelve la contradicción que existe entre la preten- 
sión de una sociedad que dice regirse por un estado de derecho y la existencia de una discriminación y estigma que se extienden por la vida familiar, comunitaria, laboral y sentimental de la persona que vive con VIH. Las rejas de la cárcel del burka están construidas del mismo material que las siluetas y desenfoques con que es presentada la realidad del VIH en nuestras sociedades modernas. La representación social en ambos casos queda fuertemente avivada por el poder de la imaginación, de toda esa carga semántica que puede añadirse gratuitamente a lo real, máxime cuando se trata de realidades que, por ser ocultas, se ven invadidas por el secreto y el misterio.

Siguiendo el razonamiento de Zîzêk (Zizek, 2004:8) acerca del poder que la fantasía ejerce en la percepción de lo real, podemos confirmar que lo real, en este caso, es la negación de esa misma realidad, esa pulsión salvaje por despojar de identidad, de existencia, algo y alguien que se considera infame, vergonzoso, como ocurre con el deseo que subyace y palpita en lo profundo de los sueños. Aquí bulle la fuerza del silencio, de la censura que nos domina y paraliza, de la implacable tiranía ejercida por el poder que soterra y sepulta su miedo a Tanathos, que repudia y devora en el anonimato una muerte tan cercana. No se puede tolerar la proximidad y la vivencia de la muerte en los nuestros, en nosotros mismos. Esta pulsión inconsciente, colectiva, intenta imponer un equilibrio falso, pero efectivo y productivo; contradictorio pero funcional dentro de una estructura social y laboral que lo acepta sin remilgos porque ella misma comparte y avanza ciega en ese falso equilibrio.

La no-representación de las personas con VIH no anula su significación. Es precisamente esta falta o negación de un significante, ausente, fantasma, la fuente suprema de su representación social, causa, entre otras, del estigma y la discriminación, como efecto o resultado del sometimiento de la sociedad a esa norma suprasensible impuesta. Paradójicamente, esta invisibilidad es compartida por la ideología que la impone, por el autor de esa norma, asimismo invisible. Es la fuerza de lo que no se ve la fuente primera de la superstición. Y como ocurre en Tabú, el filme codirigido por F. W. Murnau y R. J. Flaherty (Tabú, 1930), ese poder se deja en manos del máximo representante del Invisible: el chamán, el sacerdote, el ideólogo, encargados de imponer una fuerza contraria al instinto, a lo natural, a la vida. Una muestra de ello son las múltiples consignas que las distintas iglesias, y alguna que otra institución pública (Sontag, 1996:77), proclaman sobre la castidad, la fidelidad y la abstinencia como medidas de prevención.

De aquí que podamos entender esta imposición o censura ejercida sobre la visibilidad pública de la persona que vive con VIH como una vulneración a la inversa del Derecho a la propia imagen tal como recoge, en el caso de España, el Artículo 18.1 de la Constitución: "Derechos al honor, a la integridad personal y familiar, y a la propia imagen", y la Ley Orgánica de 5/5/82, que regula la protección civil del honor, la intimidad personal y familiar, y de la propia imagen. Si este derecho suele aplicarse habitualmente para proteger a aquellas personas que lo ven vulnerado al hacerse pública su imagen personal, o por ver representadas sin su consentimiento facetas de su vida íntima en medios de comunicación, personas que por lo general desempeñan sus profesiones en un ámbito público, se da el caso contrario en aque- 
llas, entre ellas las que viven con el VIH, a las que le es negado ese mismo derecho pero en sentido inverso. Se les niega subrepticiamente la libertad de poder identificarse públicamente a través de su propia imagen como personas que viven con ese virus, por temor a ser discriminadas social, laboral o sentimentalmente. Si la negación del derecho a la propia imagen es per se una limitación natural a la libertad de expresión y de información, en el caso que nos ocupa supone una limitación decisiva para la persona con VIH y, como consecuencia de ello, para el ejercicio de aquellas profesiones dedicadas a labores de documentación y comunicación audiovisuales. El impacto que tiene este recorte de libertad sobre la autoestima y salud de las personas con VIH es difícil de determinar en términos cuantificables por lo que solamente el análisis cualitativo puede proporcionarnos una idea aproximada, no por ello desestimable, de los hechos.

Al llevarlo tan en secreto te sientes muy sola, muy sola muchas veces, y yo creo que si no fuera una enfermedad tan tabú y vieras que hay mucha gente como tú y que no pasa nada pues no sé, mal de muchos consuelo de tontos. Lo peor para mí es llevarlo en secreto. Muchas veces lo dices para que te acepten, para sentirte bien. (Isabel, 34 años)

Yo soy una persona que me gusta contar mis cosas y que estoy mal y enseguida se me nota, y me da rabia no poder contar lo que me sucede. Entonces a mí eso me pesa mucho. Eso, yo creo, ha sido y sigue siendo lo que más daño me hace psicológicamente, el que sea un tabú y que me parece injusto que haya otras enfermedades que la gente, todo el mundo se compadezca de ellas y que tú con esta historia te lo tengas que comer con patatas, eso me parece lo peor para mí. (Julio, 28 años)

... pero una vez superado creo que el mayor problema que he tenido ha sido el estigma social, el no poder contarlo y el tener que pasar por el trago de decirle a una persona que te pasa esto y estar a expensas de haber si la persona te quiere o no te quiere porque a ti te pasa esto. (Rebeca, 36 años)

Hace 5 años no podías decir ni mu. Yo no salía ni a la calle, estuve prácticamente diez años sin pisar la calle. Porque es que me daba vergüenza que me viera la gente, exponerme. Además, me quedé muy delgadita, se me notaba que estaba muy enferma...Y ahora se acabó, no me escondo más, aquí estoy (Frente a la cámara) (Cristina, 34 años)

Ante la pregunta formulada a las 27 personas que dieron sus testimonio de vida en la producción del documental, de cuál sería la mejor forma de componer un mensaje audiovisual con fines de prevención en la población joven, la amplia mayoría de los entrevistados dijeron, entrando en una clara contradicción consigo mismos pero consecuentes con la discriminación y el estigma sufridos, que deberían ser los propios afectados, jóvenes a ser posible, los que dieran cuenta de sus experiencias y sus recomendaciones.

Yo mismo me pongo límites, yo mismo asumo el estigma. Por ejemplo, fíjate el hecho de que tú tengas que estar tomando notas a toda velocidad, ni siquiera una grabadora...(Antonio, 20 años)

Deberían ponerla como una enfermedad más y poner casos reales para que verdaderamente la juventud viera que está ahí y qué es peligroso. (Natalia, 19 años) 
Subscribiendo esa recomendación y conscientes de que sólo una minoría combatiría públicamente la discriminación y el estigma accediendo a mostrar su imagen, se nos presentaba el dilema de cómo estructurar una obra audiovisual destinada a la prevención, la información y la lucha contra la discriminación a partir de esas limitaciones. El reto de producir una obra audiovisual a partir de una imagen negada, censurada, y que a un mismo tiempo paliara los efectos negativos de esa otra imagen del seropositivo cargada de prejuicio por estar ligada de manera tendenciosa y estereotipada con grupos de población asociados a la marginalidad, la pobreza o a comportamientos considerados injustificables, era construir una imagen documental que devolviera a la sociedad la verdadera dimensión del problema, la realidad de los hechos y de las personas viviendo con el virus, con testimonios reales y una imagen que no traicionara los hechos documentales aportados por las entrevistas. Huelga decir que la imposiblidad de mostrar en su totalidad los verdaderos rostros de los protagonistas daba por perdida la batalla de antemano. El sometimiento de la obra a los imperativos de esa norma social represiva era a todas luces ineludible, había que contar irremisiblemente con esa censura impuesta que tanto afecta y condiciona el tratamiento de este problema de salud pública, para de ahí decidir un tratamiento y una política audiovisuales lo más efectivas posibles.

\section{Tratamiento audiovisual}

Para vencer esta imposición, la opción elegida para los casos en los que las entrevistas no pudieron ser grabadas en vídeo, fue la utilización de modelos, en la acepción dada al término, entre otros, por Lev Kulechov, Louis Delluc (Kazanski, 1998:114) y Robert Bresson (Bresson, 1997:19-28), y llevada a la práctica cinematográfica incontables veces empezando por la defensa apasionada de la utilización de noactores llevadas a cabo por Dziga Vertov (Vertov, 2011:245) en las primeras décadas del siglo pasado. De un total de 30 testimonios recogidos (27 con el virus y 3 familiares), doce de ellos fueron llevados a la pantalla, siendo testimoniales siete de ellos y cinco representados por modelos. La elección de los testimonios, fueran representados o documentales, se hizo con el objetivo de obtener una muestra representativa a nivel cualitativo de personas que hubieran adquirido el virus en su juventud y por transmisión sexual. No debemos olvidar que el sector destinatario de la obra era la población joven de entre 14 a 25 años, y que la meta primera era concienciar para la prevención de la infección por conductas sexuales de riesgo.

La utilización de siluetas, desenfoques, mamparas difusoras o cualquier otra técnica de ocultamiento del protagonista fue rechazada por considerarse que dicho procedimiento auspiciaba el estigma que pesa sobre la enfermedad al quedar asociado a la sensación de vergüenza y miedo. Igualmente fue desestimada la opción de llevar a cabo puestas en escena con actores jóvenes en actitudes de desenfado, y presentados en situaciones de ocio y alegría, la mayor de la veces amenizadas con bandas sonoras rítmicas y de moda, o con gags de humor, en aras de hacer una 
exposición distendida del problema con la creencia, errada a nuestro juicio, de que este tipo de lenguaje audiovisual hace más atractivo a los jóvenes el mensaje y las consignas de prevención. Estamos de acuerdo que combatir la sensación de "primus inter pares" y el "optimismo irrealista" que prevalece en la mayoría de la población joven frente a la posibilidad de contraer el virus del VIH (Ubillos, 2000:66; ) (Igartúa, Martín, Ortega y Del Río, 1997:50) debe ser uno de los principales objetivos de las obras de prevención en este grupo de población; sin embargo, como resultado de nuestra experiencia directa con las entrevistas, optamos por la realización de una obra sustentada en una imagen veraz y realista del asunto, con la convicción de que la seriedad del problema demanda un tratamiento que abogue por la madurez y responsabilidad de los jóvenes. No se trata de extremar innecesariamente la crudeza de los hechos cayendo en un naturalismo exacerbado, sino de considerar a los jovenes con el suficiente criterio e inteligencia como para ser capaces de tomar una decisión propia, libre y responsable tras examinar por sí mismos los hechos. De ahí que la técnica de representación con "modelos" utilizada en el documental pretendiera un retrato al natural de los casos prohibidos, y en ningún momento "espectacularizar" la imagen de la persona con VIH, o "transfuncionalizarla" (Zîzêk, 2004:5) con cualquier atisbo de fantasía para que, aún siendo parte de la realidad, se percibiera bajo el modo de ficción. Era preciso entonces, la vuelta a una imagen antropológica, fuera de esa búsqueda insaciable de la fotografía pretendidamente documental que persigue inconscientemente lo original, el punto de vista lleno de ingenio, curioso y singular, o incluso épico; evitar en lo posible cinematografiar lo real, estilizar o formalizar de forma larvada la realidad. En suma, se trataba de evitar en lo posible la prevalencia del autor sobre el objeto, más allá del respeto necesario hacia el modelo; ahorrar la mirada sobre uno mismo o la autocontemplación en la imagen creada, por encima de la persona retratada. La pauta fue fotografiar casi siempre en planos medios, en los escenarios elegidos por los propios protagonistas, dignificando y favoreciendo su imagen bajo la máxima de la sinceridad y el respeto. El primer plano fue utilizado en este mismo sentido en aquellas situaciones de mayor intensidad y en aras de reforzar la comunicación con el espectador en ese momento. Se evitó, por tanto, su uso como imagen afecto (Deleuze, 2009:131 y ss), como rostro abstracto, o pura representación de un carácter, un sentimiento o una pasión desligados de lo real y concreto. En definitiva, se abogó por reconstruir un significante válido y útil para los fines de prevención, y adjudicarlo a un testimonio carente de signo, de imagen; de utilizar un significante lo más fidedigno y verosímil posible a pesar de ser impostado. Claudicar ante la norma, como expusimos anteriormente, fue insoslayable, pero era necesario desmitificar en lo posible su efecto y construir una imagen acorde con una visión veraz y científica de los hechos. Reiteramos que la negación de la imagen en la enfermedad o en cualquier otro signo aviva el conocimiento supersticioso, mágico y prejuicioso del fenómeno lo que a su vez potencia el estigma y la discriminación. En sentido contrario, es ofrecer una imagen en toda su plenitud del sujeto, integral, completa, copiada del natural, más allá incluso de lo que proporciona una imagen científica en sentido estricto, pues en este caso éramos responsables de construir una imagen social de un sujeto 
con una personalidad y una historia concretas, en un escenario sentimental, familiar y comunitario propio. Y esto debía hacerse desde la óptica y conocimientos aportados por las distintas ciencias involucradas: sicología, antropología, sociología, medicina, ética, etc., con una imagen que respaldara una ideología de progreso en un sentido universal, una imagen plena y al mismo tiempo humana, sujeta en cuanto forma, estética y estilo (composición, luz, color) a un individuo concreto, con nombres y apellidos, repleto de historia.

Los modelos utilizados, a excepción de un actor amateur, nunca habían interpretado delante de una cámara, y fueron elegidos por la correspondencia y similitud de su físico y talante personal con los casos reales. Fue sorprendente hasta qué punto sus interpretaciones captaron el hálito vital, la autenticidad y el drama experimentado por las personas con VIH que representaban con tan solo conocer el material de audio original. Sus interpretaciones adolecían de cualquier forma de actuación dramática aprendida, de clichés de escuela, de trucos de actor, o de cualquier estilo; probablemente su inseguridad ante la cámara fue un fiel reflejo de aquella misma inseguridad que los entrevistados con VIH mostraron al ser grabados, en muchos casos por primera vez, durante la exposición de sus vidas ante el micrófono. Sus interpretaciones se ajustaron de forma fluida al estilo fotográfico directo y natural elegido, su realidad con la realidad de la cámara, la autenticidad de sus actuaciones de aficionados o su ingenuidad amateur favorecieron la empatía con las vidas que representaban; no supuso para ellos un reto profesional, sino una experiencia interpretativa y humana. Al representar a las personas con VIH se representaban a sí mismos, alcanzando "ese "corazón del corazón" que no se deja aferrar ni por la poesía, ni por la filosofía, ni por la dramaturgia” (Bresson, 2007:40); aprendieron a SER (modelos) en lugar de PARECER (actores) (Bresson, 2007:42), aún más, a sentirse portadores del virus, lo que en definitiva subscribía por completo el mensaje de prevención que el documental se había impuesto como meta, que no fue otro que el de que todos somos/podemos ser personas con VIH.

\section{Conclusiones}

El documental de investigación es un género cinematográfico estrechamente ligado a la actividad científica. Si bien es cierto que en la mayoría de los casos prima el interés comunicativo, didáctico o propagandístico por encima de la experimentación o la formulación de una tesis, no es menos cierto que participa de lleno de la metodología y del quehacer científicos propios de las disciplinas más afines a las ciencias sociales. En las obras documentales realizadas en estrecha colaboración con la bio-medicina, como es el caso que nos ocupa, las labores de investigación y documentación, las puestas en común con especialistas, educadores y la propia población afectada, la formulación de un enfoque a modo de hipótesis, el trabajo de campo, la recogida de datos y la articulación de una narrativa que dé sentido a toda esa información, en todo momento respaldada por criterios científicos, reafirman nuestra convicción de encontrarnos frente a obras que se sitúan entre la comunica- 
ción y la ciencia. El documental, en este caso, es fruto de la interacción entre el informador y el informante, el investigador y la población de estudio, y entre la imagen construida y la realidad de donde parte y a la que está debida.

Como resultado de la experiencia obtenida en la producción del documental Yo soy positivo ¿y tú?, se puede afirmar que la imagen de la persona con VIH con fines de difusión pública es un elemento de suma importancia en las campañas de prevención de la infección del VIH esta enfermedad, por ser un elemento catalizador de las contradicciones existentes en una sociedad que se debate entre una visión científica y mitológica del asunto. Hoy más que nunca es totalmente necesaria una semiología de la representación de esta enfermedad, que desvele sus componentes míticos e ideológicos. Las metáforas a las que está sometido el VIH/SIDA tienen unas amplias repercusiones en el devenir de la misma, en el ámbito de la salud pública y en la estigmatización de sus pacientes. Lo singular de esta representación de la persona con VIH es que carece de significante aparente, dado que su imagen es negada por gran parte de la sociedad. Una vez establecida por la medicina la diferenciación de fases de la enfermedad entre un estado latente (portador de VIH) y un estado desencadenante de patologías oportunistas (Sida) que pueden conducir a la muerte, es preciso delimitar asimismo el campo iconográfico de ambos. La sociedad parte de una representación global que se nutre de imágenes de la enfermedad en su estado avanzado o terminal, estableciéndose de este modo un significante inequívoco sustentado en una iconografía sobrecogedora y espectacular, que se expone en revistas, museos, o que sirve incluso de señuelo mercantil en vallas publicitarias (Schonberg y Bourgois, 2002:4); en definitiva, que se une a un significado contundente: el sida como enfermedad mortal, asociada a determinados grupos de población: homosexuales, drogadictos, extranjeros, africanos y minorías étnicas, y a conductas consideradas irresponsables, disolutas y amorales. Sin embargo, en el caso de la persona con VIH, carecemos de una imagen identificativa al impedirse su manifestación pública y no presentar, de ser difundida, ningún rasgo diferencial respecto del resto de la población. Se impone, pues, un silencio absoluto sobre este posible signo, es sencillamente negado por una norma social que presenta esta decisión como natural y ahistórica. Ante esta situación de bloqueo, que se traduce en un estado de discriminación y falta de libertades de la persona con VIH, es preciso crear una imagen reivindicativa de la misma, que la presente en su plenitud como persona afectada por la acción de un virus con plenos derechos como afectado y ciudadano, y evitar así tratamientos audiovisuales que redundan en una mayor estigmatización léase la utilización de máscaras, siluetas o desenfocados. De este modo, apostamos por edificar una iconografía del VIH marcada por el realismo. Es preciso devolver a la sociedad la imagen de aquello que pretende negar por razones éticas, científicas y humanas. La mitología que invade el VIH tiene sus raíces en la injusticia social, en la represión que ejercen unos contra otros, en códigos morales que perpetúan ideologías propiciadoras de estigma y discriminación al tiempo que prebendas y privilegios. En definitiva, desmitificar supone descifrar para la sensibilización y para la educación "Pero no se ahuyentan a las metáforas con sólo abstenerse de usarlas. Hay que ponerlas en evidencia, criticarlas, castigarlas, 
desgastarlas" (Sontag, 1996:172). Ante la imposibilidad de registrar con la cámara testimonios reales y directos de personas con VIH, Yo soy positivo ¿y tú? se optó por la fórmula de representar con no-actores o "modelos". Con ello, no solo creemos que, lejos de restarle veracidad e impacto, la obra redundó en el mensaje de que nos enfrentamos a una realidad estigmatizante, al tiempo que puso en evidencia de manera contundente la presión de la metáfora y la ideología. Era necesario presentar una imagen, aun reconociendo su impostura, que devolviera el rostro a sus protagonistas. A veces, no hay otra opción que eludir arteramente el mito.

\section{Bibliografía}

Barnes, D. B; Taylor-Brown, S; y Wiener, L (1997) "I Didn't Leave Y'all on Purpose": HIV-Infected Mother's Videotaped Legacies for Their Children. Qualitative Sociology, 20 (1). pp 7- 31. Nueva York, Human Science Press, Inc.

Barthes, R (2009). Mitologías. Madrid, Siglo XXI. 2009.

Bimbela, J,L. y Cruz, M,T. (1996). Sida y jóvenes. La prevención por vía sexual. Granada. Escuela Andaluza de Salud Pública. (Edición digital. Index de Enfermería Digital))

Bresson, R. (2007). Notas sobre el cinematógrafo. Madrid, Ardora.

Bretón-López, J. y Buela-Casal, G. (2005) "Evaluación del efecto de las campañas publicitarias de prevención de vih/sida en adolescentes". Psicothema. 17 (4). pp 590- 596.

Bueno, J,R y Yaosca, A (2002). "La nueva imagen de los afectados por el VIHSIDA. Un análisis cualitativo de las noticias producidas por la prensa española". En Yubero, Santiago, y Larrañaga, Elisa (Coords) (2000), Sida: una visión multidisciplinar. Cuenca, Ediciones de la Universidad de Castilla- La Mancha. pp 153-169.

Collins, H. (2002). "Respuesta de los medios de comunicación internacionales hacia el VIH durante los últimos 20 años". Barcelona, Quark: Ciencia, medicina, comunicación y cultura, 24, Abril- julio, 2002. (http:// quark.prbb.org /24/default.htm. Fecha de consulta: 29 de noviembre de 2011).

Cuevas, J. (2009). Yo soy positivo ¿y tú?. Madrid, Ed: Liga Española para la Educación, 2009. (Documental).

Deleuze, G. La imagen-movimiento. Estudios sobre cine 1. Paidós, 2011.

Espinel, M. (2003). "Sociedad del riesgo y SIDA: el caso de Sudáfrica". Política y Sociedad. Universidad Complutense de Madrid. Vol 40 (3). pp 131-152.

Fortuny Guash, C. "La infección por el VIH en el niño. Aspectos sociofamiliares". En Yubero, Santiago, y Larrañaga, Elisa (Coords) (2000), Sida: una visión multidisciplinar. Cuenca, Ediciones de la Universidad de Castilla- La Mancha. pp 105-118.

Freud, S (1972). Tótem y tabú. Obras completas Vol. V. Madrid, Biblioteca Nueva. pp 1745-1850. 
Gilman, D, L. (1994) Disease and Representation. Images of Illness from Madness to Aids. Nueva York, Cornell University Press.

Igartúa, J,J; Martín, C; Ortega, J; y Del Río, P (1997). "La publicidad de prevención del SIDA en Europa: un análisis de sus componentes persuasivos". Comunicación y cultura, 1-2, pp 43-56. Madrid, Fundación Infancia y Aprendizaje.

Igartúa, J,J; y Lopes, O, (2002). "La prevención del SIDA mediante cortos de ficción. Una investigación experimental". Zer 13 (25), noviembre. http://www.ehu.es/zer/ (2 junio de 2011)

Jodelet, D (1991) "Representaciones sociales: un área en expansión". En Sida: imagen y prevención. Páez D. et al. Ed. Fundamentos. 1991. p 25-26.

Kazanski, B. "La naturaleza del cine". En Los formalistas rusos y el cine. Albèra, François (compilador). Paidós, 1998.

Kemp, M. "A Perfect and Faithful Record: Mind and Body in Photography before 1900", en Beauty of Another Order, ed. A Thomas, New Haven and London, 1997 ,

Kirk, G. S (1970). El mito. Barcelona, Paidós, 1970.

Lévi-Strauss, C (1968). Antropología estructural. Buenos Aires, Universitaria de Buenos Aires.

Martín Fernández, R. "Manifestaciones en torno al sida. Un arte para la acción". III Congreso Online OCS (Observatorio para la Cibersociedad). 2006.

Najera Morrondo, R. (2000). "El virus del sida. Hoy y hace 10 años". En Yubero, Santiago, y Larrañaga, Elisa (Coords) (2000), Sida: una visión multidisciplinar. Cuenca, Ediciones de la Universidad de Castilla- La Mancha. pp 11-26.

Nanda, S; y Pramanik, A (2009). "HIV/AIDS in India: stigmatization as a process of communication and social relationship". Cuadernos de información 25 (II). p 105-117.

Páez, D, et al (1991 a) Sida: imagen y prevención. Madrid, Fundamentos.

Páez, D, et al (1991b). "La dimensión social del Sida como objeto representacional". En Sida: imagen y prevención. Páez D. et al. Ed. Fundamentos. 1991. p 103.

Páez, D (1991c). "Diferentes aproximaciones al concepto de representación social". En Sida: imagen y prevención. Páez D. et al. Madrid, Fundamentos. 1991.

Páez, D, et al (1997). "Afectividad, cognición y persuasión: un contraste experimental de las variables mediadoras en la prevención ante el vih/sida". Revista Electrónica de Motivación y Emoción. 4 (7) NÚMERO: 7. http://reme.uji.es/articulos/adarip1980805101/texto.html (2 de julio de 2011)

Revuelta, G; Pérez, N; Almeida, E; y De Semir, V. (2002). "El sida en los medios de comunicación. Análisis comparativo de El País, La Vanguardia y The New York Times en los 20 años de historia de la enfermedad (1981-2001)". Barcelona, Quark: Ciencia, medicina, comunicación y cultura, 24, abril-julio, 2002.

Santos, C.P et al. (2005) "Self-perception of body changes in persons living with HIV/AIDS: prevalence and associated factors". AIDS (19) (4). Lippincott, Williams \& Wilkins, pp 14-21.

Sanz, M; Vega, J, y Martínez, P (1999). Sida: aspectos médico-legales y deontológicos. Valladolid, Universidad de Valladolid. 
Schonberg, J, y Bourgois, P (2002). "Política y estética fotográfica: una documentación crítica de la epidemia de HIV entre usuarios de heroína inyectada en Rusia y Estados Unidos". International Journal of Drug Policy 13. pp 387-392.

Sontag, S (1996). La enfermedad y sus metáforas y El sida y sus metáforas. Madrid, Taurus.

Tamzali, W. (2010) El burka como excusa. Barcelona, Saga.

Terrón Blanco, J, L, (2011). "El tratamiento del VIH-sida en los periódicos españoles, una investigación colaborativa". Revista de Comunicación y Salud. 1 (1), pp. 4-17. www.revistadecomunicacionysalud.org. (15 de julio de 2011)

Ubillo, S. (2000). "Conducta sexual e infección por VIH". En Yubero, Santiago, y Larrañaga, Elisa (Coords) (2000), Sida: una visión multidisciplinar. Cuenca, Ediciones de la Universidad de Castilla- La Mancha. pp 63-94.

Usieto, R, y Sastre, J. (1996). "Prevención en la escuela: conocimientos, actitudes y conductas de riesgo". Publicación Oficial de SEISIDA, 7. pp 217-219.

Vertov, Z. Memorias de un cineasta bolchevique. Ed: Capitán Swing Libros (2011). Wojtyla, K J (1989). "Alocución de S.S. Juan Pablo II a la IV Conferencia Internacional sobre SIDA "Vivir, ¿para qué?". Vaticano, Aula del Sínodo del Vaticano. Documentos de la Iglesia.

www.pastoralsida.com.ar/documentos/juanpabloii_a.htm (2 julio de 2011)

Zîzêk, S (2004): "Fotografía, documento, realidad". Letra internacional 85. pp 4-16. 